\title{
Use Of Derivatives In The Airline Industry
}

Denis R. Abbey, (dabbey@nova.edu), Nova Southeastern University

\begin{abstract}
This paper is about the use of derivatives such as futures and option used as hedging to reduce exposure to risk in the Airline Industry. The paper considers the way derivatives are used and undertakes primary research to determine whether there is a relationship between the use of derivatives, the level of profit, the level of liabilities and executive salaries. This paper uses regression analysis and a chi-squared test. The conclusion assesses the value of these tools to airlines.
\end{abstract}

\section{INTRODUCTION}

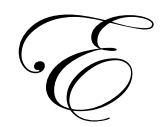

very company in any industry faces some risks according to the nature of its business. In some industries there are higher inherent risks than others. There is a variety of risk such as operational risk, exchange rate risk, liquidity risk, financial risk ect... The goal of every business is to try to eliminate, minimize or mitigate unacceptable risk following analysis of the level and probability of the risk. The most common of these is insurance, which is used where there is a high impact but a low probability of the risks involved. Where risks are likely to be faced more frequency insurance is not a viable tool and it is for these types of risks, such as changing prices of inputs for volatile materials or even events such as changes in weather, insurances is impractical (Brockett et al, 2005). The use of derivatives has become more popular in managing the exposure to risk (Stulz, 2002).

It has often been argued that for business to be successful there needs to be the management of the risk. All businesses face risk, but those who manage that risk most effectively give themselves a competitive advantage over those who face unnecessary exposure (Hoffman, 2002, Mintzberg et al, 1998). Successful and effective risk management may even be the source of a competitive advantage (Rose, 2001, Porter, 1985), but at the very least it is required to ensure survival (Nellis and Parker, 2000). In the Airline Industry, some companies like Southwest and British Airline have successfully used derivatives as their tool to manage risk exposure.

\section{HYPOTHESES}

This study considers 4 hypotheses concerning the use of derivatives in the airline industry and the result of the use of derivatives. The first hypothesis (H1) is that there is a positive relationship between the use of derivatives and higher than average liabilities. The second hypothesis $(\mathrm{H} 2)$ is that there is a positive relationship between the use of derivatives and higher than average executive salaries. We can claim there is a relationship between the use of the derivatives and either only salaries or liabilities as airlines will have these as they are paid or present whatever the situation, we need to specify exactly what the relationship is in this particular case where they are higher than average. The third hypothesis (H3) is that there is a positive relationship with a higher level of budgetary discrepancy and the forth hypothesis is that there is a positive relationship between the use of derivatives and implied taxes.

\section{METHODOLOGY}

The present study begins with a literature review that looks at the reasons for the use of derivatives by the airline industry and also at the type of derivatives used. It starts with some background on the ways airlines manage risks and the way derivatives are seen in general in the industry. This study also looks broadly at the industry and takes into consideration the level of derivatives use. In most cases, the level of the derivatives might not be disclosed in terms of operating meaning, however the value in terms of changes as a result of accenting standards is to be given, for example in the use this is SFAS 133 and we can gain an idea of the level of use and in the notes to the accounts there should be some indications. 
The hypothesis will be tested with the use of regression testing to assess if the level of derivatives may be able to predict or indicate the levels of the relevant variables. If a regression test is not suitable a chi squared test will be used to test for a correlation between two variables. There are many areas where derivatives may be used to reduce risk so a single area of risk management where derivatives are seen will be identified in the literature review and then used for the hypothesis testing.

\section{LITERATURE REVIEW}

\section{The Airline Industry}

The airline industry is an industry where high levels of risk exist. This is an industry with traditionally low levels of profit and high overhead costs along with volatile input costs. This, combined with the many influences on demand such as security concerns and fashions, currency exchange rate fluctuations along with the low profit rates increase risk. This danger and the impact of the risk can be seen when looking at the US airline industries where $51.5 \%$ of all the passenger capacity is provided by companies under a chapter 11 bankruptcy (Adams and Reed, 2005).

On Wednesday September $14^{\text {th }} 2005$, both Delta (with $15.15 \%$ of the US passenger capacity) and Northwest (with $10.67 \%$ of capacity) filed for Chapter 11 bankruptcy; however the circumstances behind these filing may be seen as very different from those already in bankruptcy. In earlier cases events such as the September 11th Terrorist attacks had a more direct impact, whereas with the later cases it appears to be related to the more regular dangers such as the fuel prices and regular demand factors.

Delta had failed to use any derivatives in order to mitigate risk associated with volatile fuel prices (Delta, 2004). Where derivatives were used, in very small levels, there was an adjustment of $\$ 31$ million loss in the 2004 accounts (Delta, 2004). Northwest did make use of derivatives but heavily limited their use to terms of not longer than 18 months (Northwest, 2004). This indicates a limited use of derivatives and as such may still support the idea that it is the use of derivatives such as hedging fuel cost that minimize exposure to risk and help companies survive, as seen with British Airways and Southwest (BA, 2005).

The use of derivatives does not guarantee profitability or a reduction in risks as seen with Japan Airlines, and other companies such as Gibson Greetings that sought to use derivatives to reduce risk and when it actually led to their down fall (Gillani, 1996). Likewise it was the abuse of derivatives that brought down the Barings Bank when a single trader used futures and options. Here there was a case of the use of derivatives appearing to correspond to all of the hypothesis with the way performance was measured, but the bank still failed as there was not a full disclosure of the real position and as such this is not a good comparator.

Furthermore, these examples also indicates that it is not only the use of derivatives, but also the way in which they are used, or not used. In the case of Northwest and Delta, these two airlines were dwelling on hopes that business would improve, with fuel process decreasing and demand increasing (Adams and Reed, 2005). As this did not happen and there was little risk management in the form of hedging, when fuel prices increased and demand dropped they were unable to survive (Adams and Reed, 2005).

\section{Derivatives}

A derivative is a financial tool that has a price which will bear a strong correlation with an underlying, or related subject; this may be currency, commodities or other financial instruments. The most popular of the markets are futures and options. When we consider futures and options, it was futures that brought down Bearings Bank with the unauthorized dealings of a single dealer; Nick Leeson. The market for derivatives is very volatile. 
Like any other traded investment derivatives are subject to the laws of supply and demand and these are extremely sensitive to these movement due to the way in which trading takes place. The majority of trading takes place on the futures basis rather that the actual basis, or spot basis.

To better understand how derivatives are used or misused, the function and operation of derivatives needs to be understood. The aspect of supply can be seen as affecting the price. This means influences which are not under the control of any producer are monitored carefully by commodity traders. The volatility of prices in general does not have a great deal of effect on the way in which the demand for primary goods fluctuates, as primary goods generally have a low elasticity.

Generally primary goods can be seen as fairly stable markets, as are other primary commodity markets such as sugar and wheat (Brown, 1999). However, in the currency markets there is a higher level of fluctuation due to the movement of the exchange rates. The futures market is different to the actual markets, the futures exchange is designed to be a compromise compared to the forward market and the risks it may present. The futures market is any contract to exchange at a future date (Howells and Bain, 1998). In commodities this is a legally binding agreement to deliver or take delivery of a certain amount of goods at a certain price (Howells and Bain, 1998).

As the contracts are standardized the amount of goods will be in standard amounts and the delivery terms will be identical throughout all the contracts (Boughey et al, 1998).

The futures exchange is a centralized trading place where the contracts which are exchanged are standardized (Feinberg, 1999). The only variable on the contracts will be the price that they are being sold at, therefore all contracts are comparable. This make comparison in the futures market slightly easier, but it also can mean that any direct comparison with the spot market may not be so simple (Demetrakakes, 1999, Androshick, 1999).

The advantage's are seen by many as outweighing the possible disadvantages as the deals would not be entered into unless both parties were happy with the deal as the spot market would still be available. However, the losses can also be very high and unexpected, and as such trading on the futures market should be reward with caution. Market participants consisted of hedgers; those people who used the market to establish prices for commercial reasons, and speculators, market participants who attempted to profit from price movement. These are, in reality the main participants in the market. The appropriate use of futures is to speculate with funds where losses can be sustained with no adverse effects or by those wanting to hedge a position to reduce their risk. Hedging can be seen as a case where derivatives may be used correctly.

Hedging is a term of use, even in colloquial language phases such as hedging ones bets, or ones position maybe heard, which is generally interpreted to mean the protection of an open position so that the risk for the future is minimized or controlled. When we consider hedging in corporate terms with financial tools this is still the correct basis for the interpretation of the term, however, here it is also more complex and requires specialist knowledge. The goal of a hedge transaction is to create a position that, once added to an investor's portfolio, will offset the price risk of another, more fundamental holding ( Reilly and Brown, 2003). This is a subject many students and business scholars will shy away from due to the in-depth knowledge that is required and the level of risks that are associated with the practice of hedging. Indeed, even companies that are able to employ specialist may still realize heavy losses, such as the recent announcement by Golden State Bancorp announced a loss of $\$ 17$ million due to hedging (Moyer, 2002).

Hedging may be used in different ways and with different goals by the various corporations. Hedging is a tool that is made use of by traders or companies that want to protect an open position. An open position is a position where losses may be incurred as the company or trader has some commodities, which can include currency, and securities, which are bought, but not sold, or sales that are not covered or hedged, meaning that fluctuations could impact on the value of the trade. The later of these is know generally as a bear position, where it is a trade, and the former, where it is goods bought and not sold is that of a bull position (Howells and Bain, 1998). This vulnerability will remain until the market position is either closed, or the use of hedging is out into place. Therefore hedging is a tool used to protect a position where a trader or company may suffer as a result of market fluctuations. 
There are two types of hedging, long hedging and short hedging. Long hedging may be seen where goods are needed to be purchased to fulfill a contract, such as fuel for the airline. This may be seen as resulting in an open position. The way a company may reduce their vulnerability is to buy a futures contract that agrees that a set amount of a commodity will be bought on a set date in the future at a set price.

The volatility is reduced as the company knows what it will have to pay for the goods it wants. The risk of the price fluctuations are transferred to the individual who has sold the futures contract, they will be very happy and make a profit if the cost is below that of the contract, if it is more then they will suffer a loss. Futures are traded on the market and there may be many trades between the supplier of the goods and the eventual purchaser.

This in turn may also lead the company to a different open position. If they have agreed to purchase goods in advance this may also be in a foreign currency, so the price, although fixed, may still be vulnerable to the price movements of the currency markets, with currencies becoming stronger or weaker. However, as well as buying a future for the raw material, the currency position may also be covered by purchasing a future for the currency that is required, so that the company has the amount that they will have to pay out in their own currency fixed with the currency future. They also risk the cost of the foreign currency falling, and on fixing the cost of the currency they can then not benefit if the price falls, meaning that in reducing the risk, they also reduce the potential to benefit if the foreign currency gets weaker. The reduced volatility is of great benefit to businesses.

Although currency can be bought on a future contract it is more likely, and also sensible that this open position may be better served with the use of an option. An option is a contact which gives the purchaser the option to purchase currency as a set price in the future. If the cost of the currency increases beyond that of the options then it will be exercised, saving the company the additional cost that they would have been subject to if the option had not been bought. If the cost of the currency falls then it would make no sense to use the option, and although the company suffers the loss of the cost of the contract, they have had the security of knowing the highest price they will have to pay for the currency. Therefore, options may be seen as more desirable, and these are far more common in the currency markets (Howells and Bain, 1998).

Overall this will not reduce the risks in their totality, as the spot prices and the options will not always move together, however, used wisely hedging can reduce the risk of international trading with open positions and it is this risk reduction that is sought by many companies (Pantzalis et al, 2001, Howells and Bain, 1998). This risk reduction with the purchase of a financial tool is know as long hedging, but is only one type of hedging.

Short hedging is where there is the sale of something to cover a future risk. For example, this may be the sale of currency that has been collected or even the home currency ready to gain foreign currency in order to pay for a different contract.

Alternatively, we may also see the need to cover a risk such as the rise of interest rates, which is relevant in many investment funds where longer term investment may be bought with the risk that interest rates may increase during the term of the investment purchase. In this later case if interest rates rise the portfolio will face a drop in overall value. The risk can be offset with the sale of a future on the financial futures market, whether of the currency at a future rate for the former case or interest rate futures for the later case. If there is a loss because of the rise of interest rates creating a lower portfolio value or a loss as a result in the currency rate fluctuation, this may be offset by the profit that has been made in the sale of the futures (Howells and Bain, 1998).

The misuse of derivatives may be by hedgers that do not buy the right hedge, by investors that do not understand the very high risks and by those who cannot afford to loose their investments.

This was seen with Baring Bank, and with the losses seen at Northwest as a result of the adjustments required by SFAS 133 which indicates a misuse of derivatives for hedging.

With this understanding of the way derivatives are used and how they may be of benefit we need to collect the data for the hypothesis testing. 


\section{FINDINGS}

To undertake any testing we need to gain some comparable figures. As many airlines work in different markets and even different currencies we will look not at the futures, but at the ratios or percentages for different measures, or seek to place the results for the airlines on a comparable scale. The hedging or use of derivative we will look at is the use of hedging on fuel costs. This appears to be the major area of activity, although other forms of hedging ore also seen, including currency. To undertake this we need to look at some airlines to identify those who do and do not use hedging in order to assess the links between the use of derivatives and the variables that are being examined. The figures used for this study are taken directly, or extrapolated from the relevant annual accounts, using the latest available set. In this set of data we will look at four airlines. We will not use Northwest as the use of derivatives here appears to be have been erroneous and as such may cause a sampling error. Also, we will not use any companies who were under a chapter 11 bankruptcy before September 2005 as their use of derivatives may be limited due to the constraints of bankruptcy. The four chosen are British Airways and Southwest as these are companies who are known to use derivatives and also have a large turnover and capacity. Delta has full annual accounts and is able to produced data for a company not using hedging. The last company chosen is another smaller airline to give a broader spectrum of the industry: Continental Airline.

Looking at British Airways, there was hedging of 523 billion pounds or approximately $\$ 926$ billion dollars and fuel costs of 1128 billion pounds or approximately $\$ 1997$ billion dollars this gives us a ratio of $46 \%$ of the fuel was hedged for the accounts May 2004, and with a declaration that this is going to increase a further 400 billion pounds or 708 billion dollars in hedging by June 2005 year. However, we will use the May 2004 figure.

Southwest explicitly state that they aim to have hedging of $80 \%$ for all there fuel costs just as Delta explicitly stated they did not have any fuel hedging for the year 2004. Continental has a high level of hedging, with $\$ 1,587$ million of fuel purchased, and hedging at \$1,351 million though express jet this gives them hedging of $85 \%$.

With the level of hedging identified the next stage is to look at the level of profit for each company, we cannot consider the other factors without this in place. The next variable is the level of liabilities, for this we are taking total liabilities as a percentage of total capital. The next hypothesis looks at the salaries of the executives. This is a more difficult assessment, so we will take the salary of the CEO, or the highest paid executive is a different position. The British Airways figure is in Pound sterling so we will convert this to dollars at a rate of $\$ 1.77$ to the British pound which was the average rate for the last twelve months. For British Airways the highest salary was for Rod Eddington, and included performance related bonuses and came out at pound; 584,000 for 2004 and for 2005 at pound; 917,000 , so we will take an average of these two figures of pound; 750,500 to convert to dollars in the following table

Table 1

\begin{tabular}{|l|c|c|c|c|}
\hline \multicolumn{1}{|c|}{ Airlines } & $\begin{array}{c}\text { Level of Hedging } \\
\text { for Fuel }\end{array}$ & $\begin{array}{c}\text { Level of Profit } \\
\text { before Tax }\end{array}$ & $\begin{array}{c}\text { Level of Liabilities } \\
\text { as Percentage } \\
\text { of Total capital }\end{array}$ & Executive Salaries \\
\hline British Airways & $46 \%$ & $5.3 \%$ & $76.1 \%$ & $\$ 1,328,385$ \\
\hline Southwest Airlines & $80 \%$ & $7.5 \%$ & $51.3 \%$ & Not Available \\
\hline Delta Airlines & $0 \%$ & $-26.5 \%$ & $126.6 \%$ & $\$ 428,092$ \\
\hline Continental Airlines & $85 \%$ & -4.4 & $97.7 \%$ & $\$ 712,500$ \\
\hline
\end{tabular}

Airline Level of hedging for fuel Level of profit before tax Level of liabilities (as a percentage of total capital)Level of highest executive salaries British Airways46\%5.3\% 76.1\%\$1,328,385 Southwest80\%7.5\%51.3\%Not available Delta0\%-26.6\%126.6\% \$428.092 Continental $85 \%-4.5 \% 97.7 \% \$ 712,500$ 
If we look at these figures we have enough data to try and chart the progress with a scatter chart and then perform a regression analysis. If we look at profit there does appear to be a positive correlation against the hedging level and the profit, the trend line indicates this.

However, it is not totally clear as seen by one point, which is the Continental Airline's point. This gives us some idea there is a relationship between performance and the level of hedging, but let's look at the level of liabilities. Again with hedging along the $\mathrm{X}$ axis we will see the following.

Table 2

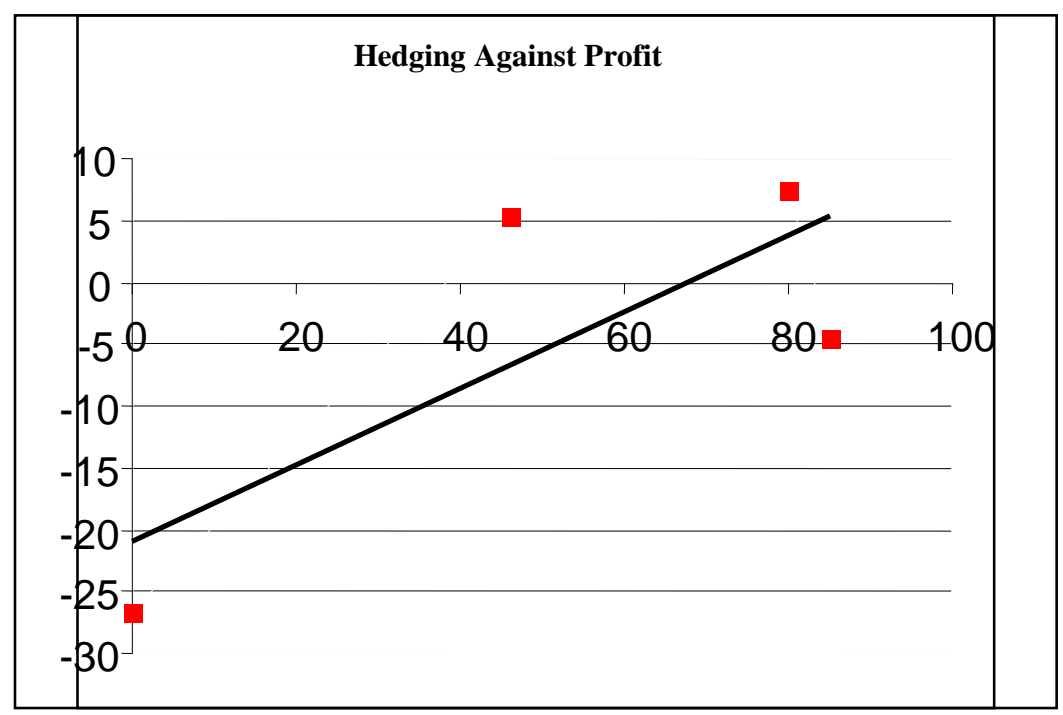

This also indicates there is a pattern, but to test this we can use some regression analysis. If we use regression analysis we can use the figures given and then look to the potential outcome of other levels of hedging. We can then compare this to other companies.

Table 3

\begin{tabular}{|l|c|c|c|c|}
\hline & British Airways & Southwest Airlines & Delta Airlines & Continental Airlines \\
\hline Hedging Level & 46 & 80 & 0 & 85 \\
\hline Level of Liabilities & 76.10 & 51.3 & 126.6 & 97.9 \\
\hline
\end{tabular}

Regression projections for levels of hedging.

Table 4

\begin{tabular}{|l|c|c|c|c|c|c|c|c|c|}
\hline \multicolumn{10}{|c|}{ Regression Projection for levels of Hedging } \\
\hline Hedging Level & 10 & 20 & 30 & 40 & 50 & 60 & 70 & 90 & 100 \\
\hline Level of liabilities & 119.58 & 106.70 & 100.98 & 95.27 & 89.55 & 83.69 & 82.14 & 94.62 & 46.64 \\
\hline
\end{tabular}

If this is correct, and it could also be used to give a guide to the levels of liabilities we would expect to see in other companies. However this gives some interesting results. For example, American Airlines has a policy to hedge 
$15 \%$ of its fuel (AA, 2005), and on this we would expect to see a level of between $119.8 \%$ and $106.7 \%$. American Airlines has a liability level of $102 \%$, so we may have a variation, but it is still broadly in line. The student may like to use these to perform a Chi squared test.

Looking at the hypothesis for the salaries the best approach is that of a hypothesis test to see if there is a relationship between the two variables.

Table 5

\begin{tabular}{|l|c|c|c|c|c|}
\hline & $\mathbf{O}$ & $\mathbf{E}$ & $\mathbf{O - E}$ & $(\mathbf{O - E}) \mathbf{2}$ & $(\mathbf{O - E}) \mathbf{2} / \mathbf{E}$ \\
\hline British Airways & $1,328,385$ & 680,438 & 647,947 & $419,835,707,033.01$ & 617008.3 \\
\hline Delta Airlines & 428,092 & 680,438 & 680,010 & $462,413,063,345.60$ & 679581.78 \\
\hline Continental Airlines & 712,500 & 680,438 & 32,062 & $1,027,991,252.29$ & 1510.77 \\
\hline Total & & & & & 1298100.9 \\
\hline
\end{tabular}

Using this in a hypothesis test is becomes clear there may be seen a relationship between the two variables to a 99\% degree of certainly. The idea of testing budgeting discrepancy is difficult as there are too few details in the available annual accounts for this to be meaningful as many discrepancies will not be apparent as they are accounted for and are often not included in the notes on the accounts, in addition, these discrepancies that are seen are adjusted for the hedging and use of derivatives as a whole and not isolated into particular uses. Moreover, it is to be noted that no former research does indicate that there is a positive correlation (Brailsford et al, 2005).

If we consider the aspect of implied taxes also sees a similar problem, with many causes and influences making it very difficult to separate out the variables in this study. Brailsford (et al, 2005) note that there is a positive correlation with the ability to decrease implied taxes and the use of datives, however, in a uniform environment the link to the net profit will be a much more important measure.

To test the implied taxes we would need to create a much larger sample to have any degree of accuracy due to the lower volatility in the figures concerned.

\section{DISCUSSION}

It appears that for the first two hypotheses are supported, either with regression analysis and/or chi squared to test the relationship. This study used a small sample, and there is possibility for some sampling errors. The pattern appears to have a normal distribution if charted, with an "n" shape. This means that the use of derivatives needs to be balanced, too little use may have a negative impact, just as too great use may also have a negative impact, rather than being a balancing act taking away all potential for gain as well as loss and indicating a too conservative approach. Furthermore, we also have to remember we are looking at only two variables in each and in reality there may be a number of other variables that may influence the outcome, as such, further research should be conducted, but at the current time both of the first two hypotheses are supported.

\section{REFERENCES}

1. $\quad$ Adams M, Reed D, (2005, Sept 15), Delta, Northwest File Chapter 11, USA Today, p.1B.

2. AMR Corporation, (2005), Annual Report 2004, retrieved 18th Sept 2005 from http://www.aa.com

3. AMR Corporation, (2005), 10K Report, retrieved 18th Sept 2005 from http://www.aa.com/content/images/amrcorp/amrcorp2004ar.pdf

4. $\quad$ Androshick Julie. (1999 August 9), Craps game, Forbes p146

5. Anonymous (2004, June 8), Don't bank on best-case scenarios; Australasian Business Intelligence.

6. Brailsford Tim, Heaney Richard, Oliver Barry, (2005, March), Use of derivatives in public sector organizations, Accounting and Finance, V45; I1; P43. 
7. British Airways (2005), Annual Report 2004/5, retrieved 18th September 2005 from http://www.bashares.com/phoenix.zhtml?c=69499\&p=IROL-financialinformation

8. Brockett, Patrick, L., Yang Chuanhou, (2005, March), Weather Derivatives and Weather Risk Management, Risk Management Insurance Review; 8.1, 127(14).

9. Curwin J, Slater R (1996), Quantitative Methods for Business Decisions, London, Thompson Business Press.

10. Delta, (2004), 10K Report 2004/5, retrieved 18th September 2005 from http://library.corporatehttp://delta.m7z.net/delta/delta/pdfs/annual_reports/ProxyStmt_2005.pdf

11. Delta, (2004), Annual Report 2004, retrieved 18th September 2005 from http://library.corporateir.net/library/11/111/111021/items/140982/NWAC_10K.pdf

12. Demetrakakes Pan (1999 April) The contract track, Food Processing v60 i4 p20 (4)

13. Feinberg Phyllis. (1999 Nov 29), Future Of Futures; Demutualization, alliances on minds. Pensions; Investments $\mathrm{v} 27 \mathrm{p} 52$

14. Howells P.G.A; Bain. K, (1998) Financial Markets and Institutions London, Longman

15. Gillani, Dilshad F. (1996, June), Managing your foreign currency exposure; CMA - the Management Accounting Magazine; 70.n5; 25(4).

16. Grant, R.M, (1997) Contemporary Strategy Analysis, Massachusetts, Blackwell Publishers Inc.

17. Hoffman Douglas G. (2002), Managing Operational Risk: 20 Firmwide Best Practice Strategies, Wiley.

18. Mintzberg H, Quinn J, Goshal S (1998) The Strategy Process (Revised European Edition), London, Prentice Hall

19. Moyer Liz. (2002, July 24), Increased Hedging Loss Forces Golden State To Lower 2Q Earnings. American Banker, p2

20. Nellis J G, Parker D, (2000), The Essence of the Business Economics, London, Prentice Hall.

21. Northwest, (2004), 10K Report 2004, retrieved 18th September 2005 from http://library.corporateir.net/library/11/111/111021/items/140982/NWAC_10K.pdf

22. Northwest, (2004), Annual Report 2004, retrieved 18th September 2005 from http://www.shareholder.com/Common/Edgar/27904/950144-05-2298/05-00.pdf

23. Pantzalis Christos; Simkins Betty J.; Laux Paul A. (2001, Winter), Operational hedges and the foreign exchange exposure of U.S. Multinational Corporations. Journal of International Business Studies, v32 i4 p793 (20)

24. Porter M.E. (1985), Competitive Advantage; Creating and Sustaining Superior Performance. New York: The Free Press.

25. Reilly K. F., Brown c. k, (2003) Investment Analysis Portfolio Management 7ed Thomson South-western

26. Rose, Jack. ;( 2001 March), Managing risks for success, CA Magazine; 134.2, 32(4).

27. Southwest (2004), 10K Report 2004, retrieved 18th September 2005 from http://phx.corporateir.net/phoenix.zhtml?c=92562\&p=irolSECText\&TEXT=aHR0cDovL2NjYm4uMTBrd216YXJkLmNvbS94bWwvZmlsaW5nLnhtbD9yZXBvPXR1 bmsmaXBhZ2U9MzIzODgxOSZkb2M9MCZhdHRhY2g9b24=

28. Southwest (2004), Annual Report 2004, retrieved 18th September 2005 from http://www.southwest.com/investor_relations/fs_financials.html

29. Stulz Rene M. (2002), Risk Management and Derivatives, South-Western College Pub.

30. Thompson J L, (1998), Strategic Management; Awareness and Change, London, Thompson Business Press.

31. Watts J (1996), Accounting in the Business Environment, London, Pitman. 